\title{
Simultaneous Viscum Pleurodesis and Bullectomy in Patients With Primary Spontaneous Pneumothorax
}

Hee Suk Jung ( $\nabla$ hsjung80@cha.ac.kr )

CHA University

Hyun Jung Kim

CHA University

\section{Research Article}

Keywords: Pleurodesis, Pneumothorax, Thoracic Surgery, Video-Assisted, Viscum album

Posted Date: July 12th, 2021

DOl: https://doi.org/10.21203/rs.3.rs-668432/v1

License: (c) (1) This work is licensed under a Creative Commons Attribution 4.0 International License.

Read Full License 


\section{Abstract}

Objectives: Although surgery is the gold standard for treatment of primary spontaneous pneumothorax (PSP), recurrence after surgery remains a concern. This study sought to evaluate the efficacy of simultaneous pleurodesis using Viscum album (VA) extract and bullectomy for the treatment of PSP.

Methods: From March 2016 to November 2020, 196 patients with PSP underwent bullectomy and intraoperative pleurodesis with VA extract at a single institution. All operations were performed through video-assisted thoracic surgery by one surgeon. Upon completion of bullectomy, a polyglycolic acid sheet was used to cover the stapler lines, and $40 \mathrm{mg}$ of VA extract was instilled over the entire chest wall before chest tube placement.

Results: The mean operating time was $18.5 \pm 5.0$ minutes (range, 10-65) and the mean indwelling time of chest drainage was $1.8 \pm 0.5$ days (range, $2-6$ ). There were no postoperative complications over grade 3 . During the median follow-up period of $36.3 \pm 18.4$ months (range, $2-57$ ), no recurrence of pneumothorax was observed.

Conclusions: The results of this study demonstrated that simultaneous Viscum pleurodesis and bullectomy provides a feasible and effective treatment option for preventing postoperative pneumothorax in patients with PSP.

\section{Introduction}

The causes of primary spontaneous pneumothorax (PSP) have not been established, but it frequently arises in thin and tall male adolescents with no relevant medical history. In asymptomatic cases with lower pneumothorax volumes, an absence of air leakage, and no further lungs expansion, patients are treated conservatively with oxygen therapy. Closed thoracostomy is the most widely used treatment method for pneumothorax. It not only expands collapsed lungs with continuous air leakage but can also be connected to a suction unit to increase the effectiveness of treatment.

Non-surgical treatment can reverse pneumothorax but typically does not prevent recurrence. PSP recurs in approximately $50 \%$ of first-onset cases and over $80 \%$ with a previous instance ${ }^{1,2}$. Bullectomy should be considered in patients with recurrent pneumothorax. However, postoperative recurrence still occurs after bullectomy with rates ranging from 6 to $14 \%^{3-6}$. Thus, several additional procedures including the use of fibrin sealants, radiofrequency therapy, and simultaneous pleurectomy or pleurodesis with bullectomy have been described to minimize the recurrence of PSP $5,7-10$.

In the present study, we evaluated the efficacy of intraoperative chemical pleurodesis using Viscum album (VA) extract after video-assisted thoracic surgery (VATS) bullectomy for the treatment of PSP.

\section{Methods}


Between March 2016 and November 2020, 196 patients underwent VATS bullectomy and intraoperative pleurodesis using VA extract for PSP at our hospital. All patients underwent chest radiography and chest computed tomography (CT) scans before surgery. Patients who had catamenial pneumothorax (related to menstruation), traumatic pneumothorax, or underlying lung disease (secondary pneumothorax) were excluded from the study. The eligibility criteria for surgery were as follows: recurrent pneumothorax, pneumothorax on the opposite side (contralateral pneumothorax), bilateral pneumothorax, tension pneumothorax, bulla or blebs over $1 \mathrm{~cm}$ on chest CT, air leakage for more than 3 days, and special occupations (e.g., pilots or divers). Postoperative recurrent pneumothorax was defined as a pneumothorax confirmed by chest radiography or CT scan that occurred 30 days or more after removal of the chest tube. The protocol was approved by the Institutional Review Board of Bundang CHA Medical Center (No. 2021-06-038), and the requirement for informed consent was waived due to the retrospective nature of the study. All procedures performed in this study were in accordance with the ethical standards of the national research committee.

\section{Procedures}

All operations were performed by a single surgeon. Patients were placed under general anesthesia in the lateral decubitus position with a double lumen endotracheal tube. A camera port was inserted through the seventh intercostal space (ICS) along the mid-axillary line after lung deflation. Two working ports were inserted, one over the fifth ICS anterior axillary line and the other over the fourth ICS posterior axillary line. Any bulla or blebs identified on 3-mm $30^{\circ}$ thoracoscope were resected with an endoscopic stapling device (EndoGIA, Auto Suture Company, Norwalk, CT, USA). After bullectomy, the stapling sites were covered with an absorbable polyglycolic acid sheet (Neoveil; Gunze Ltd., Kyoto, Japan) and fibrin glue. A mixture of 40 mg of VA extract (European Mistletoe, ABNOBA viscum F; ABNOBA Helmittel GmbH, Pforzheim, Germany) and $50 \mathrm{~mL}$ of normal saline was administered into the pleural space by needle instillation (Video and Fig. 1). Care was taken to ensure that the mixed agent was sprayed as directly towards the parietal pleura and evenly applied to the entire chest wall and surface of the diaphragm. All ports were removed under direct vision and a 20-Fr chest tube was inserted through the port sites followed by lung inflation. After surgery, the connected tube line was lifted up approximately $30 \mathrm{~cm}$ above the patient for 30 minutes to avoid outflow of the sclerosing agent, allowing air to pass (Fig. 2). After drainage of the agent, the chest tube was connected to a low-pressure suction system at $-10 \mathrm{~cm} \mathrm{H}_{2} \mathrm{O}$.

\section{Postoperative care and follow-up}

Postoperative analgesics included routine oral non-steroid analgesics and intravenous injection of pethidine hydrochloride if the pain became intolerable. Chest pain or discomfort was recorded using a numeric rating scale (NRS) from 0 to 10; severe pain was defined as a NRS score of 7 or more. Chest radiography was taken immediately postoperatively and every morning. The criterion for removal of the chest tube was full expansion of the lung on chest radiography with cessation of air leakage. After 
discharge from the hospital, patients were monitored at the outpatient clinic 2 weeks, 1 month, and 6 months postoperative via chest radiography and physical examination. Patients who had passed the 6month follow-up period were asked to report the recurrence of pneumothorax by telephone questionnaire once a year.

\section{Results}

The mean age of the 196 patients who underwent surgery for PSP was $22.3 \pm 7.0$ years old (range, 15-40), and males accounted for $96 \%$. In total, 36 out of the 196 patients underwent treatment for recurrent pneumothorax; 10 who had received conservative treatment with oxygen therapy; 20 , closed thoracostomy; 6 who underwent bullectomy and were transferred to our hospital for recurrent pneumothorax. There was no difference in the incidence rate of PSP on the left and right side. The mean interval from first operation for PSP was $6.4 \pm 3.8$ months (range, $0-12$ ) for ipsilateral recurrent pneumothorax and $14.3 \pm 6.1$ months (range, 6-23) for contralateral pneumothorax, respectively (Table 1). Mean operating time was $18.5 \pm 5.0$ minutes (range, 10-65) and mean indwelling time of chest drainage was $1.8 \pm 0.5$ days (range, 2-6). There were no postoperative complications including bleeding, atelectasis, pneumonia, arrhythmias, or wound infections. During the median $36.3 \pm 18.4$ months (range, 2-57) follow-up period, no recurrences or symptoms that suggested pneumothorax were observed (Table 2).

\section{Discussion}

One of the most important issues in the treatment of PSP is preventing recurrence. Although surgery is the most effective treatment for PSP, the recurrence rate of pneumothorax remains $5-15 \%$ after thoracoscopic surgery ${ }^{3-6,11,12}$. In order to minimize recurrence rate of postoperative pneumothorax, chemical pleurodesis has been performed simultaneously with resection or sequentially. Chen et al. reported a significant reduction in pneumothorax recurrence in a group who received additional minocycline pleurodesis after bullectomy (2\%) compared with those who only underwent bullectomy ( $8 \%$ ) 10. A similarly reduced recurrence rate was also demonstrated by Loubani et al. who showed that intraoperative tetracycline pleurodesis following surgery versus those who received surgery alone 9 .

Sterile talc without asbestos is the most widely used agent in chemical pleurodesis. However, this agent should be used carefully and only in selected patients because it can cause serious complications such as acute respiratory distress syndrome, systemic embolism, and acute pneumonitis. Other sclerosing agents include a derivative of tetracycline, autologous blood, povidone iodine, OK-432, etc., but these are associated with higher rates of recurrence of pneumothorax than sterile talc ${ }^{13-18}$.

VA extract is one of several sclerosing agents under investigation for their potential ability to increase efficacy and fewer complications ${ }^{19}$. This extract is widely used in the treatment of many diseases in traditional and complimentary medicine due to its anti-tumor effects and immune modulation ${ }^{20}$. VA extract was first used by Salzer et al. in 1977 for chemical pleurodesis in the treatment of malignant 
pleural effusion to stimulate antitumor immunity rather than mechanical sclerosis ${ }^{21}$. Cho et al. reported that chemical pleurodesis using VA extract was a successful means of treating malignant pleural effusion in 79\% (49/62) of patients ${ }^{22}$. This drug is also used as an effective sclerosing agent in cases of congenital chylothorax and pneumothorax with continuous airleakage ${ }^{23-27}$. The complications of Viscum pleurodesis that have been reported are mostly minor and include transient pleural effusion, a mild burning sensation, and mild fever episodes; there have been no reports of serious complications.

Although chemical pleurodesis is an additional technique to prevent the recurrence of postoperative pneumothorax, it has several side effects, such as aggravated postoperative pain due to pleural irritation or inflammation. Moreover, there is a possibility of restrictive pulmonary dysfunction caused by pleural adhesions which can make repeat pleurolysis challenging. However, several papers reported that pain after pleurodesis was well controlled via patient-controlled-analgesia or narcotic analgesics, and patients did not exhibit a significant degree of pulmonary hypofunction compared to those in the group free from pleurodesis ${ }^{5,10}$. In a patient undergoing VATS excision for a thymic cyst 6 months after PSP surgery in our study, there was no difficulty performing pleurolysis with dissection via electrocautery due to scant and loose adhesions between the visceral and parietal pleura (Fig. 3). We used 40mg of VA extract, which was approximately one-third of the dose for malignant effusion. Besides, conventional pleurodesis requires 4 to 6 hours of indwelling time, whereas VA extract was drained out 30 minutes after surgery in the recovery room. This dosage and indwelling time for Viscum pleurodesis with bullectomy were effective for preventing pneumothorax recurrence without serious complications; however, further research is needed to confirm our findings.

This is an uncontrolled, single center retrospective report, and without a control group to evaluate this agent against other sclerosing agents (e.g. doxycycline, talc, iodine, bleomycin, fluorouracil, silver nitrate etc.). This field requires a multi-center comparative study to sort out the agent with the least toxicity, adverse effect, and greatest long-term efficacy.

\section{Conclusion}

Surgical resection alone is not sufficient for preventing recurrence of pneumothorax. A comparative study with other sclerosants is needed to determine the efficacy of VA extract in pleurodesis, but this study showed good results with less morbidity. We suggest that simultaneous Viscum pleurodesis and VATS bullectomy could be a feasible and effective treatment option for patients with PSP.

\section{Abbreviations}

- CT (computed tomography)

- ICS (intercostal space)

- NRS (numeric rating scale)

- POD (postoperative day) 
- PSP (primary spontaneous pneumothorax)

- Tx (treatment)

- VA (Viscum album)

- VATS (video-assisted thoracic surgery)

\section{Declarations}

Conflict of Interest Statement:

The authors have nothing to disclose with regard to commercial support.

Sources of Funding Statement:

No funding was provided.

Notation of prior abstract publication/presentation:

None

Financial/nonfinancial disclosures:

None declared.

\section{References}

1. Sahn, S. A. \& Heffner, J. E. Spontaneous pneumothorax. N Engl J Med 342, 868-874, doi:10.1056/NEJM200003233421207 (2000).

2. Estrada Salo, G. et al. [Spontaneous pneumothorax: pleurodesis with an iodo-povidone hydroalcoholic solution]. Arch Bronconeumol, 39, 171-174 https://doi.org/10.1016/s03002896(03)75352-6 (2003).

3. Ogawa, K. et al. OK-432 pleurodesis for the treatment of pneumothorax in patients with interstitial pneumonia. Respir Investig, 56, 410-417 https://doi.org/10.1016/j.resinv.2018.05.003 (2018).

4. Lee, Y. C. et al. Pleurodesis practice for malignant pleural effusions in five English-speaking countries: survey of pulmonologists., 124, 2229-2238 https://doi.org/10.1378/chest.124.6.2229 (2003).

5. Aelony, Y. Talc pleurodesis vs iodopovidone., 123, 1318-1319 author reply 1319https://doi.org/10.1378/chest.123.4.1318 (2003).

6. Chang, Y., Cho, D., Cho, K. \& Cho, M. Viscum pleurodesis is as effective as talc pleurodesis and tends to have less adverse effect. Support Care Cancer, 28, 5463-5467 https://doi.org/10.1007/s00520020-05405-0 (2020). 
7. Kovacs, E. Effects of Viscum album extract therapy in patients with cancer: relation with interleukin6, soluble interleukin-6 receptor, and soluble gp130. J Altern Complement Med, 10, 241-246 https://doi.org/10.1089/107555304323062220 (2004).

8. Salzer, G. [The local treatment of malignant pleural exudations with Iscador (a drug obtained from Misteltoe). Preliminary report (author's transl)]. Osterr Z Onkol, 4, 13-14 (1977).

9. Cho, J. S. et al. Chemical Pleurodesis Using Mistletoe Extraction (ABNOVAviscum((R)) Injection) for Malignant Pleural Effusion. Ann Thorac Cardiovasc Surg, 22, 20-26 https://doi.org/10.5761/atcs.oa.15-00230 (2016).

10. Song, K. S., Keum, D. \& Kim, J. B. Chemical Pleurodesis Using Doxycycline and Viscum album Extract. Korean J Thorac Cardiovasc Surg, 50, 281-286 https://doi.org/10.5090/kjtcs.2017.50.4.281 (2017).

11. Park, J. B., Lee, S. A., Lee, W. S., Kim, Y. H. \& Hwang, J. J. The management of chemical pleurodesis with viscum album in patients with persistent air leakage. J Thorac Dis, 10, 371-376 https://doi.org/10.21037/jtd.2017.12.67 (2018).

12. Kim, J. D. et al. Chemical pleurodesis with Viscum album L. extract for secondary spontaneous pneumothorax in elderly patients. J Thorac Dis, 12, 5440-5445 https://doi.org/10.21037/jtd-20-708 (2020).

13. Cho, H. J. et al. Chemical pleurodesis using a Viscum album extract in infants with congenital chylothorax. Eur J Pediatr, 173, 823-826 https://doi.org/10.1007/s00431-014-2283-9 (2014).

14. Noh, D., Park, J. S. \& Lee, D. Y. Acute Respiratory Distress Syndrome after Viscum album Pleurodesis for Primary Spontaneous Pneumothorax. Korean J Thorac Cardiovasc Surg, 50, 64-67 https://doi.org/10.5090/kjtcs.2017.50.1.64 (2017).

15. 15. Estrada Salo, G. et al. [Spontaneous pneumothorax: pleurodesis with an iodo-povidone hydroalcoholic solution]. Arch Bronconeumo/ 39, 171-174, doi:10.1016/s0300-2896(03)75352-6 (2003).

16. 16. Ogawa, K. et al. OK-432 pleurodesis for the treatment of pneumothorax in patients with interstitial pneumonia. Respir Investig 56, 410-417, doi:10.1016/j.resinv.2018.05.003 (2018).

17. 17. Lee, Y. C. et al. Pleurodesis practice for malignant pleural effusions in five English-speaking countries: survey of pulmonologists. Chest 124, 2229-2238, doi:10.1378/chest.124.6.2229 (2003).

18. 18. Aelony, Y. Talc pleurodesis vs iodopovidone. Chest 123, 1318-1319; author reply 1319, doi:10.1378/chest.123.4.1318 (2003).

19. 19. Chang, Y., Cho, D., Cho, K. \& Cho, M. Viscum pleurodesis is as effective as talc pleurodesis and tends to have less adverse effect. Support Care Cancer 28, 5463-5467, doi:10.1007/s00520-02005405-0 (2020).

20. 20. Kovacs, E. Effects of Viscum album extract therapy in patients with cancer: relation with interleukin-6, soluble interleukin-6 receptor, and soluble gp130. J Altern Complement Med 10, 241246, doi:10.1089/107555304323062220 (2004). 
21. 21. Salzer, G. [The local treatment of malignant pleural exudations with Iscador (a drug obtained from Misteltoe). Preliminary report (author's transl)]. Osterr Z Onkol 4, 13-14 (1977).

22. 22. Cho, J. S. et al. Chemical Pleurodesis Using Mistletoe Extraction (ABNOVAviscum((R)) Injection) for Malignant Pleural Effusion. Ann Thorac Cardiovasc Surg 22, 20-26, doi:10.5761/atcs.oa.1500230 (2016).

23. 23. Song, K. S., Keum, D. \& Kim, J. B. Chemical Pleurodesis Using Doxycycline and Viscum album Extract. Korean J Thorac Cardiovasc Surg 50, 281-286, doi:10.5090/kjtcs.2017.50.4.281 (2017).

24. 24. Park, J. B., Lee, S. A., Lee, W. S., Kim, Y. H. \& Hwang, J. J. The management of chemical pleurodesis with viscum album in patients with persistent air leakage. $J$ Thorac Dis 10, 371-376, doi:10.21037/jtd.2017.12.67 (2018).

25. 25. Kim, J. D. et al. Chemical pleurodesis with Viscum album L. extract for secondary spontaneous pneumothorax in elderly patients. J Thorac Dis 12, 5440-5445, doi:10.21037/jtd-20-708 (2020).

26. 26. Cho, H. J. et al. Chemical pleurodesis using a Viscum album extract in infants with congenital chylothorax. Eur J Pediatr 173, 823-826, doi:10.1007/s00431-014-2283-9 (2014).

27. 27. Noh, D., Park, J. S. \& Lee, D. Y. Acute Respiratory Distress Syndrome after Viscum album Pleurodesis for Primary Spontaneous Pneumothorax. Korean J Thorac Cardiovasc Surg 50, 64-67, doi:10.5090/kjtcs.2017.50.1.64 (2017).

\section{Tables}

Table 1. Clinical demographics of the study subjects

\begin{tabular}{|ll|}
\hline Characteristics & Total $(\mathrm{n}=196)$ \\
\hline Age (years) at operation & $22.3 \pm 7.0(15-40)$ \\
\hline Sex (male:female) & $188(95.9): 8(4.1)$ \\
\hline Affected side & \\
\hline Right & $72(36.7)$ \\
\hline Left & $112(57.2)$ \\
\hline Bilateral & $12(6.1)$ \\
\hline Tx history for ipsilateral pneumothorax & $36(18.4)$ \\
\hline Observation & $10(5.1)$ \\
\hline Closed thoracostomy & $20(10.2)$ \\
\hline Operation & $6(3.7)$ \\
\hline
\end{tabular}

Data are presented as No. (\%) or mean \pm standard deviation (range) 
$\mathrm{Tx}=$ treatment

Table 2. Surgical and postoperative results

\begin{tabular}{|ll|}
\hline Outcomes & Value \\
\hline Operation time (min) & $18.5 \pm 5.0(10-65)$ \\
\hline No. of bullectomies & $2.2 \pm 2.1(1-5)$ \\
\hline Body temperature & \\
\hline POD \#0 / POD \#1 & $37.8 \pm 0.5(36.9-38.6)$ / 37.4 \pm 0.6 (36.4-38.4) \\
\hline Pain scale (NRS) & \\
\hline POD \#0 / POD \#1 & $4.3 \pm 3.2(2-6) / 2.5 \pm 1.8(1-4)$ \\
\hline Postoperative chest tube drainage (days) & $1.8 \pm 0.5(2-6)$ \\
\hline Postoperative hospital stay (days) & $2.3 \pm 0.7(2-7)$ \\
\hline Postoperative complications (grade $\geq 3)$ & $0(0)$ \\
\hline Recurrence & $0(0)$ \\
\hline Follow-up period (months) & $36.3 \pm 18.4(2-57)$ \\
\hline
\end{tabular}

Data are presented as No. (\%) or mean \pm standard deviation (range)

POD = postoperative day

NRS = numerical rating scale

\section{Supplementary Video}

The video file is not available with this version.

\section{Figures}




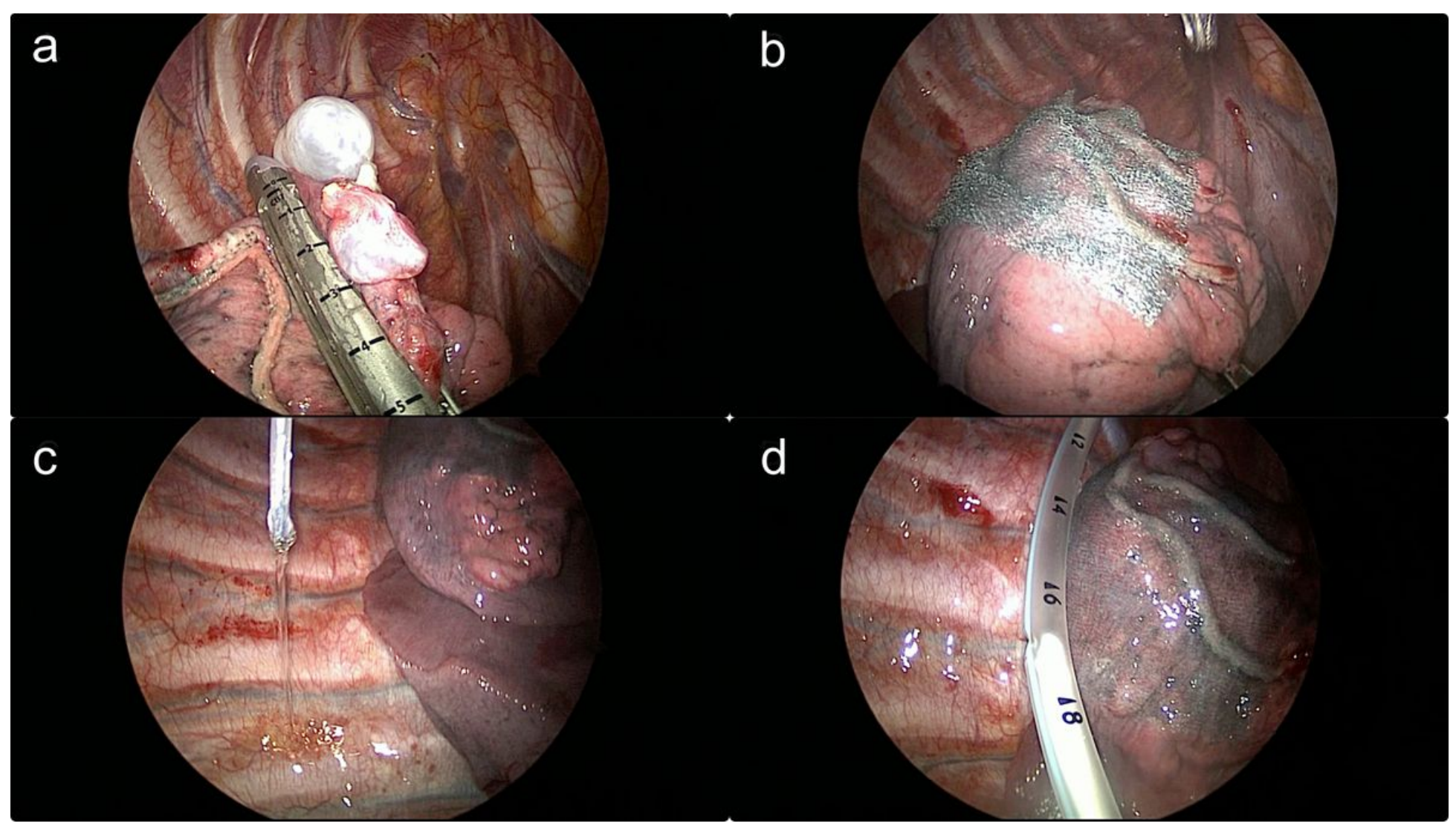

\section{Figure 1}

(a) Resection of bulla using an autostapler; (b) Stapler line reinforcement with a polyglycolic acid sheet;

(c) Administration of a mixture of $40 \mathrm{mg}$ VA extract and saline into the pleural space by needle instillation;

(D) Chest tube placement before lung inflation 


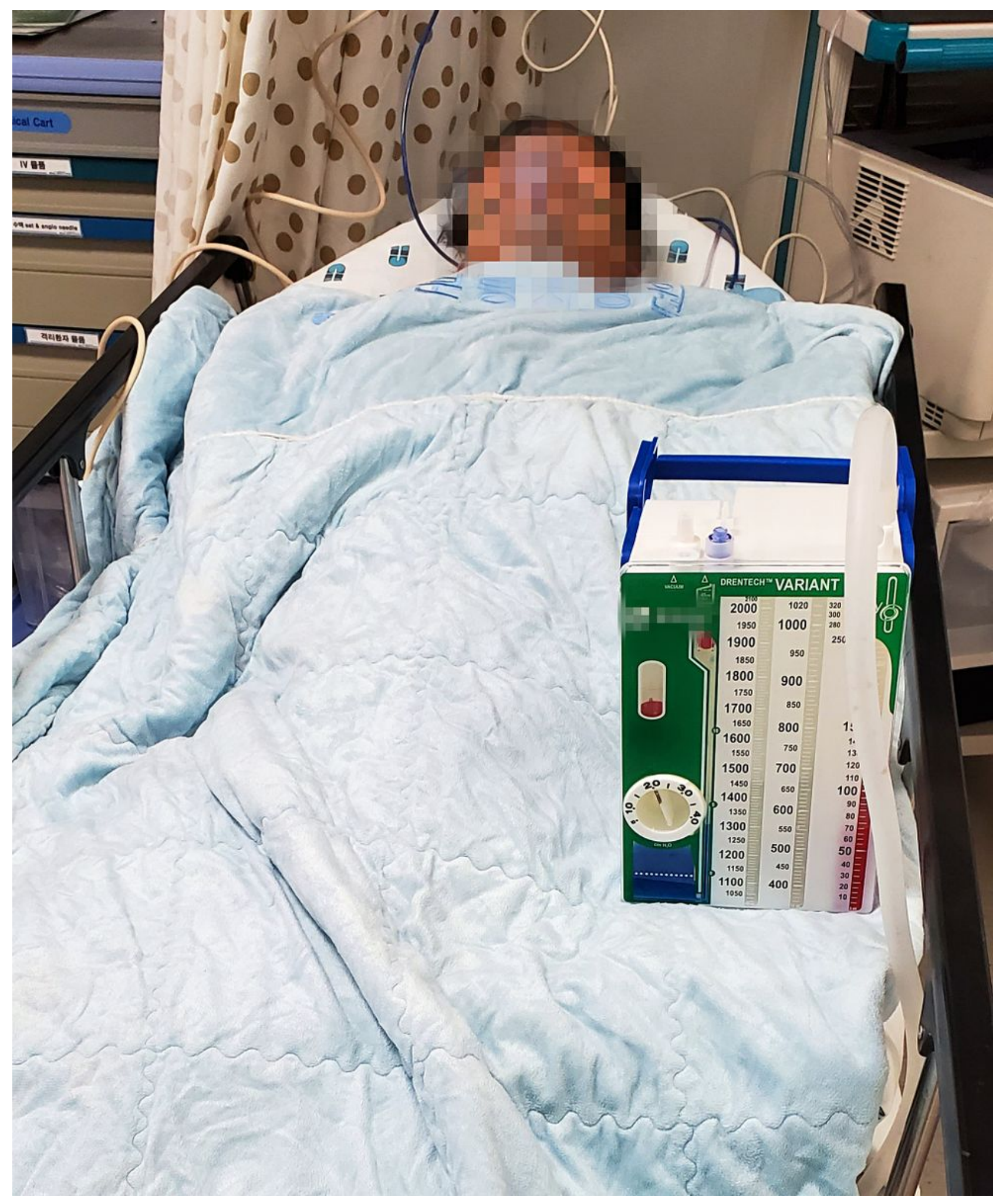

Figure 2

After the operation, the chest tube was lifted approximately $30 \mathrm{~cm}$ above the patient for 30 minutes without clamping in the recovery room. 


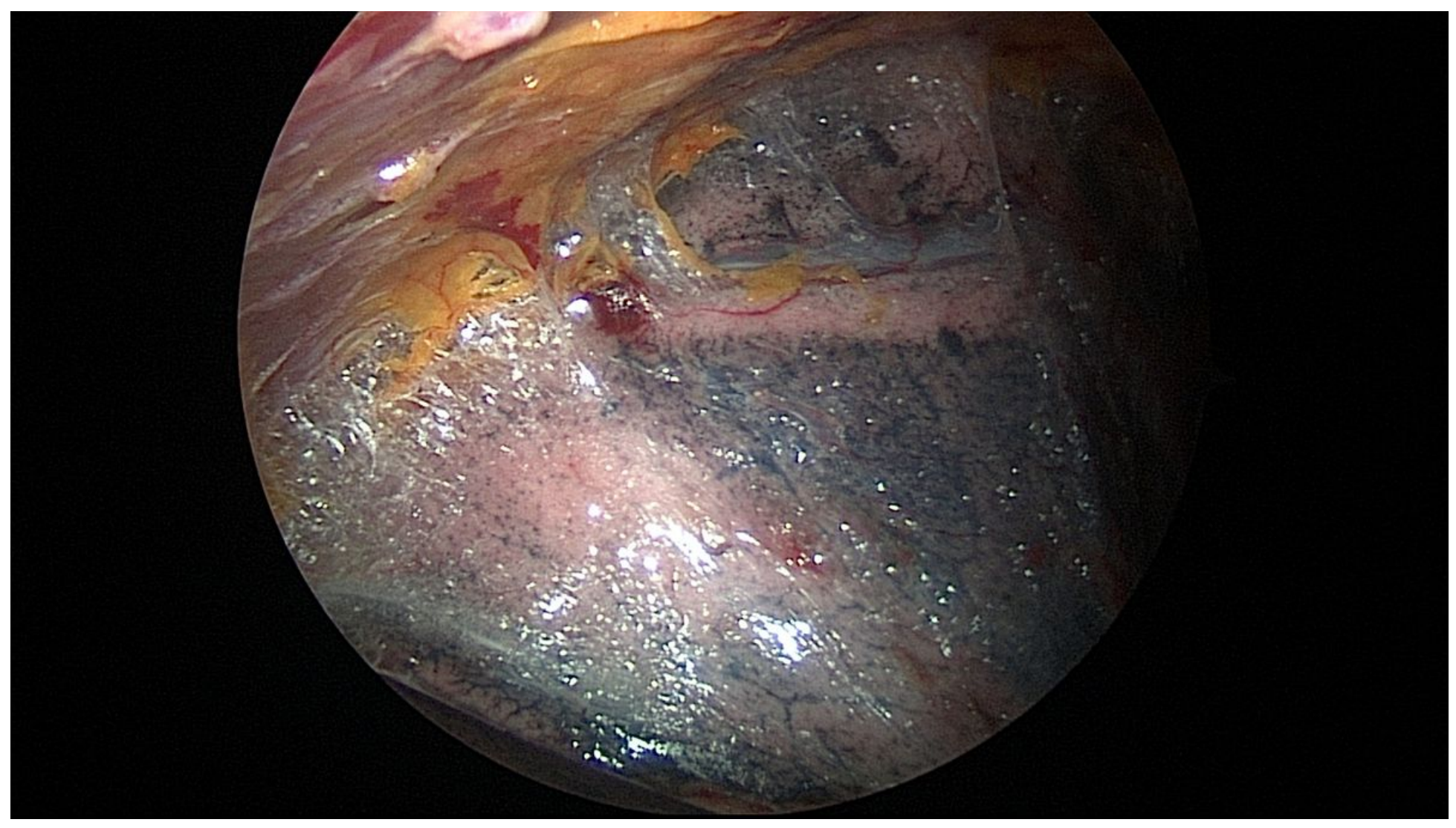

\section{Figure 3}

Intraoperative photograph of the flimsy pleural adhesions after simultaneous Viscum pleurodesis and bullectomy 